\title{
In memory of Craig Newell
}

This issue of the journal is dedicated to the memory of Craig Newell, who died suddenly a few weeks before this issue was published and shortly after submitting his revised paper to the journal. It was my pleasure as editor to work with Craig, who was unfailingly gracious and good humored-not only as an author dealing with the deadlines and revisions demanded by an irascible editor, but also in his generous efforts in serving as a reviewer of another article submitted to the journal. Craig had returned to graduate school after retiring from a lifetime of teaching, further exploring his passion for both mathematics and teaching in becoming part of the Mathematics Education cohort in the Ph.D. Program; he had recently successfully completed his comprehensive exams. He was also teaching pre-service teachers. Craig also keenly enjoyed sports and spending as much time as possible in the outdoors: local rivers, forests, and mountains, and those farther a field - he had once climbed Mt. Kilimanjaro. In facilitating the continuance of Craig's lifelong work and interest in mathematics education, donations may be made to the Craig Newell Memorial Mathematics Education Scholarship Fund Care, care of Simon Fraser University, Advancement Office, 8888 University Drive, Burnaby, BC, V5A 1 S6.

Charles Scott

Simon Fraser University 